\title{
The Acquisition of Intensifiers versus Reflexive Pronouns
}

\author{
Insa Gülzow \\ ZAS, Berlin \\ GUELZOW@zas.gwz-berlin.de
}

\begin{abstract}
The ultimate goal of the study is to examine the acquisition of intensifiers in English and German. In this paper an overview of the first results regarding four L1 English-speaking children will be given. Contrary to previous claims in the literature (e.g. Thomas 1990), it will be argued that intensifiers are used by children in early phases of language acquisition. Intensifiers play an important role in early phases of language acquisition since they can be used to express the wish either to be included or excluded in a certain action and thus contribute to structuring a central aspect of the child's discourse.
\end{abstract}

\section{Introduction}

Intensifiers most probably exist in all languages and display very specific syntactic and semanic properties. While in English intensifiers are formally identical with reflexive pronouns, other languages like German, Slovak or Yoruba use distinct expressions (table 1). Intensifiers may agree in person, number, gender and case with the NP they interact with. Typically, several related expressions exist (1). One expression of the lexical field of intensifiers can be regarded as the core member and is least restricted in terms of syntactic distribution. In English, the prototypical representative of the class of intensifiers is $x$-self, in German it is selbst:

(1) English: $\quad x$-self, personally, own, by $\mathrm{x}$-self $(\mathrm{x}$-self $=$ myself, yourself, himself, herself, etc. $)$ German: selbst, persönlich, leibhaftig, eigen, von selbst

Table 1: Examples of reflexive pronouns and intensifiers in four different languages

\begin{tabular}{|c|c|c|c|c|}
\hline & \multicolumn{2}{|c|}{ reflexive pronouns } & \multicolumn{2}{|l|}{ intensifiers } \\
\hline English & $\begin{array}{ll}1^{\text {st }} & \text { myself } \\
2^{\text {nd }} & \text { yourself } \\
3^{\text {rd }} & \text { himself } / 1 \\
& \text { (oneself) }\end{array}$ & $\begin{array}{l}\text { ourselves } \\
\text { yourselves } \\
\text { themselves }\end{array}$ & $\begin{array}{l}1^{\text {st }} \text { myself } \\
2^{\text {nd }} \text { yourself } \\
3^{\text {rd }} \text { himself/herself/itself } \\
\text { (oneself) }\end{array}$ & $\begin{array}{l}\text { ourselves } \\
\text { yourselves } \\
\text { themselves }\end{array}$ \\
\hline German & $\begin{array}{l}1^{\text {st }} \text { mich } \\
2^{\text {nd }} \text { dich } \\
3^{\text {rd }} \text { sich }\end{array}$ & $\begin{array}{l}\text { uns } \\
\text { euch } \\
\text { sich }\end{array}$ & $\begin{array}{ll}1^{\text {st }} & \text { selbst } / \text { selber } \\
2^{\text {nd }} & \text { selbst } / \text { selber } \\
3^{\text {rd }} & \text { selbst } / \text { selber } \\
\end{array}$ & $\begin{array}{l}\text { selbst/selber } \\
\text { selbst/selber } \\
\text { selbst/selber }\end{array}$ \\
\hline Slovak & $\begin{array}{ll}\text { A } & \text { seba/sa } \\
\text { G } & \text { seba/sa } \\
\text { D } & \text { sebe/si } \\
\text { I } & \text { sebou } \\
\text { L } & \text { sebe } \\
\end{array}$ & $\begin{array}{l}\text { seba/sa } \\
\text { seba/sa } \\
\text { sebe/si } \\
\text { sebou } \\
\text { sebe }\end{array}$ & $\begin{array}{l}\text { M/F/N } \\
\text { N sám/sama/samo } \\
\text { A samého/samú/samo } \\
\text { G samého/samej/samého } \\
\text { D samému/samej/samémı } \\
\text { I samým/samou/samým } \\
\text { L samom/samej/samom }\end{array}$ & $\begin{array}{l}\text { sami/samy } \\
\text { samých/samy } \\
\text { samých } \\
\text { samým } \\
\text { samými } \\
\text { samých }\end{array}$ \\
\hline Yoruba & $\begin{array}{l}1^{\text {st }} \text { ara } \mathrm{mi} \\
2^{\text {nd }} \text { ara re } \\
3^{\text {rd }} \text { ara rè }\end{array}$ & $\begin{array}{l}\text { ara wa } \\
\text { ara nyín } \\
\text { ara won }\end{array}$ & $\begin{array}{l}1^{\text {st }} \text { funrarami } \\
2^{\text {nd }} \text { funrarare } \\
3^{\text {rd }} \text { funrararè }\end{array}$ & $\begin{array}{l}\text { funrarawa } \\
\text { funrarayin } \\
\text { funrarawon }\end{array}$ \\
\hline
\end{tabular}


In the following I will use the classification of König (1991) who has distinguished between an adnominal use of intensifiers (2), an adverbial exclusive use (3) and an adverbial inclusive use (4). Intensifiers are always in association with an NP, in the examples given the subject NP. For comparision, an example of a reflexive pronoun is given in (5).

(2) The queen herself came to the meeting.

adnominal

(3) I always cook dinner myself.

adverbial exclusive

(4) I know what it means to have a constant headache, adverbial inclusive I used to have a constant headache myself.

(5) I saw myself in the mirror.

reflexive

In their adnominal use, intensifiers are mostly right-adjacent to the NP they interact with, in the adverbial use various positions are common. In contrast to reflexive pronouns, intensifiers do not constitute separate NPs and their syntactic status is that of adjuncts, not that of arguments (Siemund 1997). This is an important point to note, because the fact that reflexive pronouns can be replaced by other NPs without risking the grammaticality of the utterance will be used as a criterion for differentiating intensifiers and reflexive pronouns in the acquisition data of the English children in a first step of the analysis.

\section{Previous Results}

Studies on the acquisition of intensifiers are rare. In fact there do not seem to be any studies focussing exclusively on the acquisition of intensifiers. Two studies examining the acquisition of reflexive pronouns mention intensifiers, but regard them as a secondary phenomenon occurring sometime during or even after the acquisition of reflexive pronouns (McDaniel, Cairns and Hsu 1990, Thomas 1990).

In McDaniel, Cairns and Hsu's experimental study (1990) children's knowledge of the binding principles A, B and C (Chomsky 1981) were tested. With respect to Principle A McDaniel, Cairns and Hsu made the interesting observation that children go through phases in which first they accept sentences like (6) then reject them as not grammatical and later on accept them again before they finally reach a stage in which they make adult judgements.

(6) Himself is washing Grover.

According to McDaniel, Cairns and Hsu, acceptance of self-expressions in subject position can be motivated either by the interpretation of reflexive pronouns as consisting of a possessive plus self, or in a later phase by the only partial acquisition of intensifiers once reflexive pronouns have been correctly categorized as NPs. Some of the younger children in their study $(2 ; 9-3 ; 8)$ confirmed a grammar type characterized by the former statement while it was some of the older children in the study $(3 ; 8-6 ; 7)$ who confirmed a grammar type characterized by the latter statement. This implies that in an early phase of acquiring self-expressions children use reflexive pronouns but not intensifiers. It should be noted at this point that McDaniel, Cairns and Hsus' statements refer only to the adnominal use of intensifiers and ignore the possible influence of the adverbial use of intensifiers.

Thomas (1990, p.273 footnote 28) claims that only „one emphatic reflexive appeared in child speech among the CHILDES transcripts I searched". It should be noted though that 
Thomas regarded some expressions as reflexive pronouns which would be coded as intensifiers in the present study. Contrary to Thomas' claim it will be argued here that the self-expressions in the two examples cited below $(7)+(8)$ are neither reflexive pronouns nor "the object of an optional preposition $b y$ ", but examples of two different syntactic construction both representing the adverbial exclusive use of intensifiers. In (8) the self-expression appears in a prepositional phrase and not in the same clause as the antecedent does. Although self-expressions in prepositional phrases are not completely unusual in English, they either occur as the complements of local prepositions in the so-called snake-sentences (9) or in examples of logophoricity (10). In both sentences (9) and (10) the self-expressions are examples of reflexive pronouns, therefor constitue NPs and can thus be replaced by a bare pronoun without risking the grammaticality of the sentence. This stands in sharp contrast to the type of sentence stated in (7) and (8). It is not possible to replace the self-expressions with a personal pronoun or any other NP without risking the grammaticality of the sentence. Sentences (7) and (8) both contain intensifiers of the type adverbial exclusive. As will be discussed in more detail below, there is good reason to believe that the difference between the use of an intensifier $x$-self $(7)$ in the meaning of without assistance is not identical with the structure by $x$-self $(8)$ in which the preposition is left out. Rather two different syntactic types of the adverbial exclusive intensifier can be distinguished which is reflected by different meanings of otherwise identical sentences.

(7) I want chose it myself.

(Eve 2;3)

(8) Yes sure can she eat by herself

(Nina 2;5)

(9) He found a snake near him/himself.

(10) He sat down at the desk and opened the drawers. In the right hand one was an envelope addressed to himself. (Lodge, Changing Places)

\section{The study}

The data were taken from the CHILDES database. The data of four children Adam, Eve and Sarah of the Brown corpus (11) and Abe (12) of the Kuczaj corpus were examined.

$\begin{array}{lll}\text { Brown-corpus } & \text { Adam: } 2 ; 3,4-5 ; 2,0 & 55 \text { recordings } \\ & \text { Eve: } 1 ; 6,0-2 ; 3,0 & 20 \text { recordings } \\ & \text { Sarah: } 2 ; 3,5-5 ; 1,6 & 136 \text { recordings } \\ \text { Kuczaj-corpus } & \text { Abe: } 2 ; 4,24-5 ; 0,11 & 210 \text { recordings }\end{array}$

So far the analysis of the data includes three steps. First the occurence of reflexive pronouns was compared to the occurence of intensifiers. All child utterances containing the forms self or selv or a more complex version therof were extracted. Subsequently, the utterances were coded in three categories:
a. self-expressions used as a marker of reflexivity
b. self-expressions representing an intensifier
c. any other self-expression

In a second step of the analysis, intensifiers were coded according to whether they were used adnominally, adverbially exclusive or adverbially inclusive. Following Baker (1995) who regards intensifiers as markers of discourse prominence, his conditions for the use of 
adnominal intensifiers were used for their identification (14). Examples for each of the four conditions are given in (15): queens rank high on a social scale, the conductor is regarded as central in a concert. Sue is identified in relation to her husband and in the last example himself relates to the story-teller the perspective of whom is taken by the reader.

(14) Adnominal intensifiers relate a centre $X$ to a periphery $Y$ of alternative values, such that
a. $\mathrm{X}$ has a higher rank than $\mathrm{Y}$ in a real-world hierarchy.
b. $\mathrm{X}$ is more important than $\mathrm{Y}$ in a specific situation.
c. $\mathrm{Y}$ is identified relative to $\mathrm{X}$ (kinshipterms, part-whole, etc.)
d. $\mathrm{X}$ is the subject of consciousness, centre of observation, etc. (logophoricity).

(15) a. The queen herself came to the meeting.

b. The orchestra was satisfied with the concert. The conductor himself thought it was awful.

c. Sue's husband work as a teacher. Sue herself is a doctor.

d. He sat down at the desk and opened the drawers. In the right hand one was an envelope addressed to himself. (Lodge, Changing Places)

Adverbial exclusive intensifiers relate to an agent subject and characterize the referent as the maximally interested party, who maximally benefits (16) or suffers (17) from the result of a relevant action (Siemund 1997). An intensifier was coded adverbial exclusive if the intensifier could be replaced by without assistance with mainly preserving the meaning.

(16) She built the house herself.

(17) He dropped his favourite vase himself.

Adverbial inclusive intensifiers occur in the context of interaction (18), reproaches (19) and expressions of empathy (20), (Siemund 1997). An intensifier was coded as adverbial inclusive if the intensifier could be replaced by too with mainly preserving the meaning.

$$
\text { A: Could I borrow your car? B: I'm sorry, but I need it myself. }
$$
How can you complain about loud children when you have loud children yourself? Don't tell me. I have a headache myself.

The results of the second analysis prompted a third step in which two different syntactic constructions expressing the adverbial exclusive use of intensifiers were compared. Since none of the children produced vast numbers of self-forms in single sessions, all sessions which were recorded during six successive months were grouped together if not indicated otherwise. The data of the youngest child Eve was only considered in the first analysis, since she only started to produce intensifiers and reflexive pronouns at the end of the recordings.

\section{Results and discussion}

\subsection{Reflexive pronouns versus intensifiers}

Over the period of the recordings all four children produced both utterances with reflexive pronouns and utterances with intensifiers (table 2 and charts 1-3). Although reflexive 
pronouns were used more frequently, three of the four children used intensifiers in total numbers amounting to at least $60 \%$ of the total number of reflexive pronouns.

Table 2: Children's use of reflexive pronouns versus intensifiers

\begin{tabular}{l|ll|ll}
\hline & $\begin{array}{l}\text { total } \\
\text { reflexive pronouns }\end{array}$ & $\begin{array}{l}\text { total } \\
\text { intensifiers }\end{array}$ \\
\hline Adam $(2 ; 3-5 ; 2)$ & $82(100 \%)$ & 50 & $(61 \%)$ \\
\hline Sarah $(2 ; 3-5 ; 1)$ & 35 & $(100 \%)$ & 7 & $(20 \%)$ \\
\hline Abe $(2 ; 4-5 ; 0)$ & 65 & $(100 \%)$ & 47 & $(72 \%)$ \\
\hline Eve $(1 ; 6-2 ; 3)$ & 2 & $(100 \%)$ & 7 & $(350 \%)$ \\
\hline
\end{tabular}

From the data of the four children in the study it is impossible to describe a clear pattern of emergence concerning the succession of reflexive pronouns and intensifiers. Before they reached the age of 3;0 all four children used both reflexive pronouns and intensifiers. Although the charts seem to suggest that a period of six months may pass between the occurrence of reflexive pronouns and intensifiers, a more detailed look at the individual sessions reveals that once utterances with either reflexive pronouns or intensifiers occurred the other function emerged within the next two months. Generally the figures show that children who produce self-expressions in reflexive contexts will also produce utterances

Adam: reflexive pronouns vs. intensifiers (chart 1)

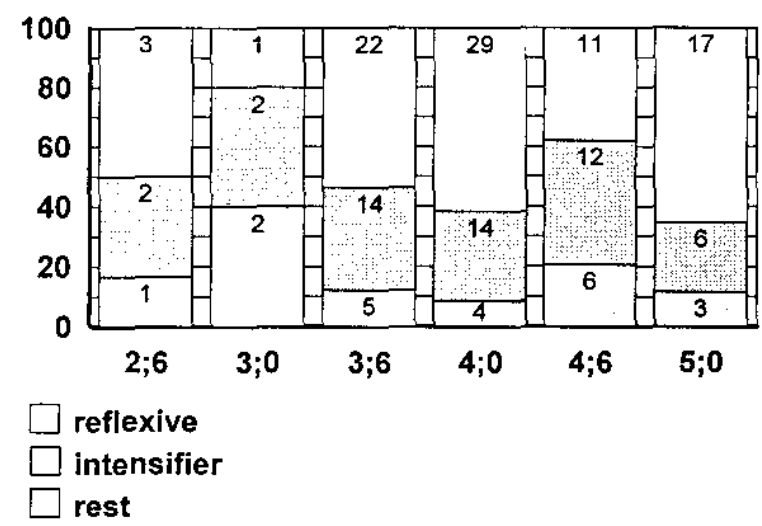

Sarah: reflexive pronouns vs. intensifiers (chart 2)

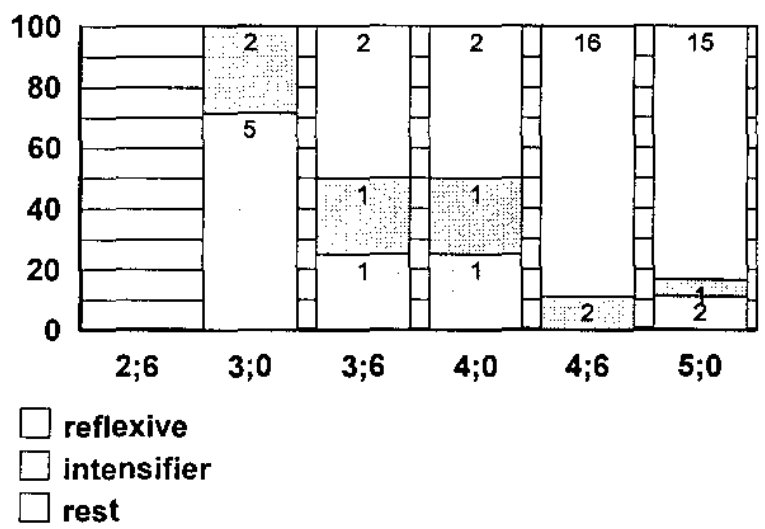


Abe: reflexive pronouns vs. intensifiers (chart 3)

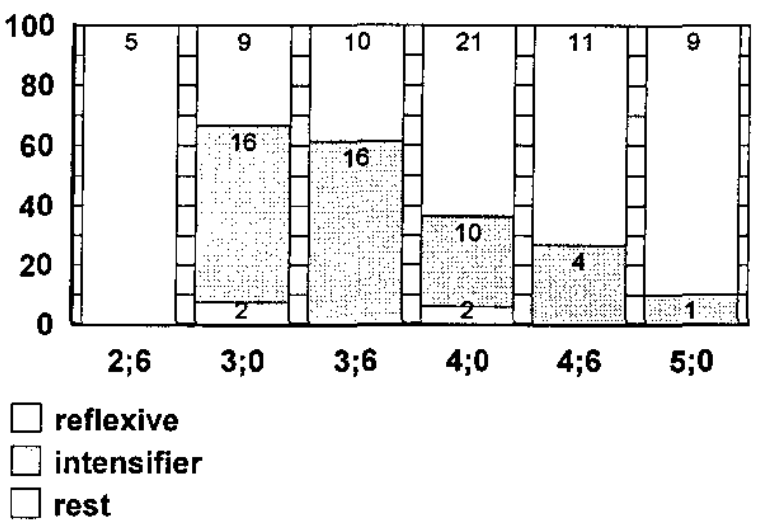

containing intensifiers and vice versa. From the production data alone it is impossible to tell whether there is a short delay for the appearance of the other function once either reflexive pronouns or intensifiers are used. The data seem to suggest though that once self-expressions appear they do so in both the syntactic function of reflexive pronouns and intensifiers.

\subsection{Types of intensifiers used}

The second step of the analysis showed that the children in the study did not use adnominal intensifiers and rarely used adverbial inclusive intensifiers. This is an interesting result if we consider the statements made by McDaniel, Cairns and Hsu (1990). All children in their study who could be characterized by having only partially acquired the adnominal use of intensifiers accepted not only self-expressions in subject position (21) but also subject NPs that contained an adnominal intensifier plus a corresponding pronoun (22).

(21) Himself is patting Grover.

(22) He himself is going to school.

Although no examples of the sentence type (22) could be found in the data of the present study, the 'rest' category contained some examples in which children used a self-expression for a subject NP, cf. table 3 and sentences (23)-(27). The age at which self-expressions in subject position occur in the production data $(4 ; 3$ and $3 ; 10,25)$ is consistent with the results of McDaniel, Cairns and Hsu's study $(3 ; 8-6 ; 7)$. They observe that at this age the acceptance of target-like sentences which contain a correct combination of an NP and an agreeing intensifier (22) co-occurs with the acceptance of sentences like (21) which are not target-like and have a bare self-expression in subject position. The claim though that this co-occurrence is motivated because the children are in the process of acquiring the adnominal intensifier is left largely unexplained. The four examples which were so far found in the production data of the present study are too few to inspire a different explanation. It should be born in mind though that other studies have shown (Budwig 1989) that children use non-target person references in subject position (me, my, name) for pragmatic reasons. With respect to the discourse properties of adnominal intensifiers it is also not quite clear from the examples given in sentences (23)-(27) why the children should be interested in creating a centre-periphery scenario. 
Table 3: Self-expressions in subject position

\begin{tabular}{|c|c|c|c|c|c|c|c|}
\hline & & $2 ; 6$ & $3 ; 0$ & $3 ; 6$ & $4 ; 0$ & $4 ; 6$ & $5 ; 0$ \\
\hline \multirow[t]{2}{*}{ Adam: } & rest & 1 & 2 & 5 & 4 & $6(100 \%)$ & 3 \\
\hline & $\begin{array}{l}\text { self-expression in } \\
\text { subject position }\end{array}$ & 0 & 0 & 0 & 0 & $3(50 \%)$ & 0 \\
\hline \multirow[t]{2}{*}{ Sarah } & rest & 0 & 5 & 1 & 1 & 0 & 1 \\
\hline & $\begin{array}{l}\text { self-expression in } \\
\text { subject position }\end{array}$ & 0 & 0 & 0 & 0 & 0 & 0 \\
\hline \multirow[t]{2}{*}{ Abe } & rest & 0 & 2 & 0 & $2(100 \%)$ & 0 & 0 \\
\hline & $\begin{array}{l}\text { self-expression in } \\
\text { subject position }\end{array}$ & 0 & 0 & 0 & $2(100 \%)$ & 0 & 0 \\
\hline
\end{tabular}

(23) *ADA: which one myself would like \# huh?

(24) *ADA: now myself has to park.

(25) *ADA: now myself has to park.

$(4 ; 3,0$, at a later time during the recording)

(26) *ABE: because your self would do it.

(27) *ABE: your self would hate you.

By far the most utterances were usages of the adverbial exclusive intensifier (charts 4-6). Although the fact that no adnominal intensifiers occurred might be explained by syntactic difficulties, it seems more appropiate to argue that the semantics of adnominal intensifiers

Adam: types of use (chart 4)

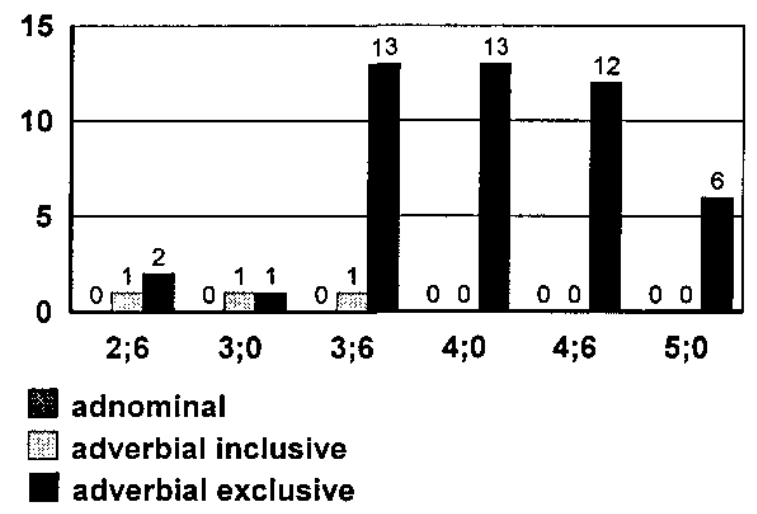

Sarah: types of use (chart 5)

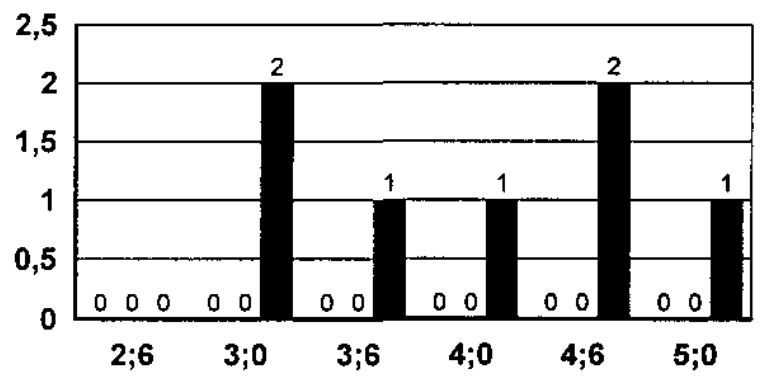

adnominal

adverbial inclusive

adverbial exclusive 
Abe: types of use (chart 6)

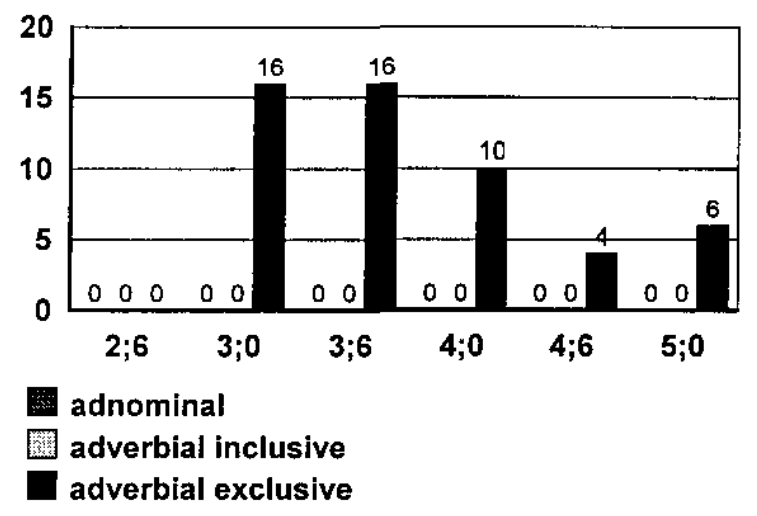

have little attraction for children. The interaction of parents with their young children (under age five) usually offers few opportunities to talk about e.g. social hierarchies. From this perspective the fact that the children used only few adverbial inclusive intensifiers was much more surprising. A total of three utterances containing an adverbial inclusive intensifier could be identified. These three utterances were all produced by the one child Adam. In this case it does not seem plausible to claim that the semantics of adverbial inclusive intensifiers are irrelevant for children. Quite the contrary, expressing that they want to be included in a certain action, like playing with a special toy, eating cookies, being picked up, is highly relevant in a child's discourse. The reason that in such situations children did not use adverbial inclusive intensifiers seems to lie in the fact that English offers an alternative expression serving a very similar function: too. The extra effect of myself in otherwise indentical sentences, singling out the associated referent in contrast to alternative referents, does not seem important (28)+(29). Too is sufficient for expressing the wish that one wants to be included. From a typological perspective the adverbial inclusive use of an intensifier is the one most likely missing in a language.

(28) I want some cookies myself.

(29) I want some cookies too.

Regarding the adverbial exclusive use of intensifiers, their semantics are also highly relevant in children's discourse: children often wish to express that they rather than anybody else want to perform a certain action. In this case English offers no alternative expression to $x$-self. In German it is possible to use allein ('alone') instead of the intensifier selbst $(30)+(31)$, but this is not an option in English. The use of alone (33) implies that the referent was without company while myself in (32) implies that the referent did not receive any help in carrying out the action. In German both sentences (30) and (31) mean that the referent did not receive assistance in carrying out the action. The interpretation of allein in (31) meaning that no one else was present is possible but according to native speakers strongly dispreferred.

(30) Ich habe meine Schuhe selbst angezogen.

(31) Ich habe meine Schuhe allein angezogen.

(32) I put on my shoes myself.

(33) I put on my shoes alone. 


\subsection{Adverbial exclusive intensifiers: two different syntactic constructions}

Only the data of two of the children, Adam and Abe contained high numbers of intensifiers and thus high numbers of utterances with adverbial inclusive intensifiers. In the case of these two children an interesting picture emerged. In over $70 \%$ or in over $80 \%$ of the cases (table 4) these children did not use the bare adverbial exclusive intensifier $x$-self as in (34a) and (35a) but the more complex expression by $x$-self as in (34b) and (35b).

a. *ADA: hey \# I wan(t) (t)a do it this time myself

b. *ADA: I put de wheels on de \# all by myself

a. *ABE: ok I'll hold it and do it myself ok?

b. *ABE: yeah this time I'm gon (t)a wash it all by myself

Table 4: Children's use of adverbial exclusive intensifiers

\begin{tabular}{|c|c|c|}
\hline & $\begin{array}{l}\text { total excl. } \\
\text { intensifiers } \\
x \text {-self }\end{array}$ & $\begin{array}{l}\text { total excl. } \\
\text { intensifiers } \\
\text { by } x \text {-self }\end{array}$ \\
\hline Adam $(2 ; 3-5 ; 2)$ & $47 \quad(100 \%)$ & $39(83 \%)$ \\
\hline Sarah $(2 ; 3-5 ; 1)$ & $7 \quad(100 \%)$ & $2 \quad(29 \%)$ \\
\hline Abe $(2 ; 4-5 ; 0)$ & $47 \quad(100 \%)$ & $35(74 \%)$ \\
\hline
\end{tabular}

Table 5: Adam's mother's use of adverbial exclusive intensifiers

\begin{tabular}{l|l|l}
\hline & $\begin{array}{l}\text { total excl. } \\
\text { intensifiers } \\
x \text {-self }\end{array}$ & $\begin{array}{l}\text { total excl. } \\
\text { intensifiers } \\
\text { by } x \text {-self }\end{array}$ \\
\hline Adam-mother & $25(100 \%)$ & $16(64 \%)$ \\
\hline
\end{tabular}

Why do children use a more complex expression by $x$-self? The simplest answer would be because adults do so too. So far, only the data of Adam's mother has been analysed in this respect (table 5). The results contain nothing surprising. Adam's mother uses by $x$-self instead of $x$-self in the majority of cases. What is the difference in meaning in sentences containing the bare intensifier $x$-self versus sentences containing the expression by $x$-self? Native speakers describe the difference between sentences (36a) and (36b) in that sentence A implies that the cake is self-made but not necessarily exclusively baked by the referent of the subject. $\mathrm{He}$ or she might have received some help.
a. I made the cake myself.
b. I made the cake by myself.

In sentence B on the other hand, the cake is not only self-made but also produced exclusively by the referent of the subject without the help or interference of another party. In other words, the use of by $x$-self stresses the fact that in carrying out a certain action the referent of the NP with which the intensifier is associated is the only agent and did not receive assistance or help. 
The claim that the use of by $x$-self stresses the agency of the subject can be supported by a closer look at the construction of sentences containing by $x$-self. The first important point to note is that sentences containing by $x$-self are in many languages similar to passive sentences containing a $b y$-phrase. Nevertheless they are different in that sentences with $b y x$-self can only be active. Although it is well-documented that the $b y$-phrase in passives is not limited to a single thematic role, it has been shown in a recent study by Fox and Grodzinsky (1998) that young children $(3 ; 6-5 ; 5)$ are unable to transmit the external $\theta$-role of the predicate to the by-phrase. Based on a comparison of verbal passive with nominals, Fox and Grodzinsky argue that the children interpret $b y$-phrases on the basis that the preposition by is capable of directly assigning a $\theta$-role to its complement. While the $b y$-phrase in verbal passives receives any $\theta$-role of the external argument, $b y$-phrases in nominals are limited to the thematic roles AGENT, INSTRUMENT and CREATOR/POSSESSOR. In other words sentences (37b)-(39b) are grammatical because they contain an AFFECTOR $b y$-phrase. If the object remains unaffected, nominals containing a by-phrase become ungrammatical (40b) $+(41 b),((40)$ and (41) from Fox and Grodzinsky 1998).

(37) a. The police rescued the hostages.

b. the rescue of the hostages by the police

(38) a. The house was damaged by bombs.

b. the damage of the house by bombs

(39) a. Rodin created sculptures

b. (the creation of) sculptures by Rodin

(40) a. The package was received by John.

b. the receipt of the package (*by John)

(41) a. Harry was feared by John.

b. the fear of Harry (*by John)

From this observation Fox and Grodzinsky conclude that in verbal passives too, by can directly assign an AFFECTOR role to the $b y$-phrase. This explains why the children in their study had no difficulties interpreting sentences like (42) and (43) in which the by-phrase expresses an AGENT and thus an AFFECTOR role, but failed when asked to interpret sentences like (44) in which the $b y$-phrase expresses a non-AFFECTOR role.

(42) The rock star is being chased by the koala bear.

(43) The boy is getting touched by the magician.

(44) The boy is seen by the horse.

None of the children in the present study were older than those in Fox and Grodzinsky's study. If at this age children consistently interpret phrases headed by the preposition by as representing an AFFECTOR role two interesting consequences follow. First, a sentence like (36b) contains an AGENT I and an AFFECTOR in the PP. Second, intensifiers are not arguments and thus no co-reference can be expressed between the referent of the external argument and the complement of the PP, because myself in by myself has no direct referent but is associated with the referent of the NP it agrees with. It will be argued here that it is exactly this property of the construction by $x$-self that makes the extra stress on the agency of the subject possible: the intensifier myself in the example does not introduce an additional referent. On the other hand myself is in association with the subject NP and the fact that it is part of a phrase introduces the possibilty of a further thematic role. As a consequence, the AFFECTOR role is mapped onto the external argument with which the intensifier agees and 
which means that one single referent is the bearer of two thematic roles: in the example (36b) AGENT and AFFECTOR. By mapping an AFFECTOR role on the referent of the NP that is associated with the intensifier of the $b y$-phrase, independent of its own $\theta$-role the status of the subject becomes more agent-like.

That the $\theta$-role of a $b y$-phrase containing an intensifier has some effect on the $\theta$-role of the NP the intensifier agrees with is especially clear if we look at sentences with a non-prototypical AGENT in subject position. In sentences (45a)-(47a) the door, the wheel and the screen are inanimate subjects ranking low in terms of a prototypical AGENT (Dowty 1990). Contrary to the fact that sentences like (45a)-(47a) are described as deagentive, by itself has a similar effect on the subject NP as in (36b). Sentences (45a)-(47a) imply that no agent or cause is immediatly identifiable. These sentences can only be constructed with action verbs that do not require an animate subject, but name an action that can be caused by an agent. In some cases the verbs can be used either intrasitively (45a)+(46a) or transitively $(45 b)+(46 b)$ or the verb can somehow be constructed transitively (47b). If it is not possible to construct a sentence with an AGENT in subject position the sentence becomes akward (48b) or impossible (49b). The interpretation of sentences like (45a)-(47a) rests on the fact that the intransitive member the verb-pair is dependent on the existence of the transitive member of the pair and is in many cases derived from it. Parallel to passives it will be argued here that sentences (45a)-(47a) as well as sentences (45c)-(47c) contain an implicit agent which means that although the agent is not expressed, it is assumed to be there. While in sentences (45a)-(47a) the use of the construction by $x$-self highlights the fact that the agent is at the time unknown or not identifiable, sentences $(45 \mathrm{c})-(47 \mathrm{c})$ obscure the agent for no special reason.
a. The door closed by itself.
b. Peter closed the door.
c. The door closed.
a. The wheel turned by itself.
b. Peter turned the wheel.
c. The wheel turned.
a. The screen went dark by itself.
b. Peter caused the screen to go dark.
c. The screen went dark.
a. The flower smelled *by itself.
b. ?Peter caused the flower to smell.
a. The mountain was too high *by itself.
b. *Peter caused the mountain to be too high.

\section{Conclusion}

The first steps in the analysis of the data of children acquiring English have shown that children do use intensifiers at early stages in language acquisition. While adnominal intensifiers do not occurr, adverbial intensifiers are used to express both the wish to be included in a certain action and to carry out a certain action without the assistance of others. Parallel to previous results documented in the literature, it could be shown that children are sensitive to the notion of AGENT. 


\section{Literaturverzeichnis}

Baker, C.L. (1995): Contrast, discourse prominence, and intensification, with special reference to locally free reflexives in British English. Language 71, 63-101.

Budwig, N. (1989): The linguistic marking of agentivity and control. Journal of Child Language 16, 263-284. Chomsky, N. (1981): Lectures on government and binding. Dordrecht: Foris.

Dowty, D.R. (1991): Thematic proto-roles and argument selection. Language 67, 574-619.

Fox, D. and Grodzinsky, Y. (1998): Children's Passive: A View from the By-Phrase. Linguistic Inquiry 29 (2), 311-332.

König, E. (1991): The meaning of focus particles: A comparative perspective, London, Routledge.

McDaniel, D., Cairns, H. and Hsu, J. (1990): Binding principles in the grammars of young children. Language Acquisition 1 (1), 121-138.

Siemund, P. (1997): Intensifiers. Doctoral Dissertation.

Thomas, M. (1990): Young children's hypotheses about English reflexives. In: J. Sokolov and Catherine Snow (eds.), Handbook on research in language development using CHILDES, Hilldale: Lawrence Earlbaum. 